\title{
MUC gene abnormalities in sporadic and hereditary mucinous colon cancers with Microsatellite Instability
}

\author{
Chiara Pastrello ${ }^{\mathrm{a}}$, Manuela Santarosa ${ }^{\mathrm{a}}$, Mara Fornasarig ${ }^{\mathrm{b}}$, Roberto Sigon ${ }^{\mathrm{c}}$, Tiziana Perin ${ }^{\mathrm{d}}$, \\ Giuseppe Giannini ${ }^{\mathrm{e}}$, Mauro Boiocchi ${ }^{\mathrm{a}}$ and Alessandra Viel ${ }^{\mathrm{a}, *}$ \\ ${ }^{\mathrm{a}}$ Department of Preclinical Research and Epidemiology, Centro Riferimento Oncologico, IRCCS, Aviano (PN), \\ Italy \\ ${ }^{\mathrm{b}}$ Department of Medical Oncology, Centro Riferimento Oncologico, IRCCS, Aviano (PN), Italy \\ ${ }^{\mathrm{c}}$ Department of Surgical Oncology, Centro Riferimento Oncologico, IRCCS, Aviano (PN), Italy \\ ${ }^{\mathrm{d}}$ Department of Diagnostics, Centro Riferimento Oncologico, IRCCS, Aviano (PN), Italy \\ ${ }^{\mathrm{e}}$ Department of Experimental Medicine and Pathology, University La Sapienza, Rome, Italy
}

\begin{abstract}
Aim of this study was verifying whether mucin producing colon cancers (CRCs) could develop through a molecular pathway involving microsatellite instability (MSI) and MUC gene alterations. Out of 49 CRCs expressing variable amounts of mucin, $22(44.9 \%)$ were MSI-H and 5 (10.2\%) were MSI-L. MUC genes were analyzed by Southern blotting and extra bands were evident in the Variable Number Tandem Repetition (VNTR) regions of MUC2 (5 cases) and MUC5AC (2 cases), but not $M U C 1$ and MUC4 genes. Since the somatic VNTR abnormalities were detected in 6 MSI-H and in 1 MSI-L tumors, they seem to be peculiar of mismatch repair defective CRCs. Our finding suggests that alteration and/or loss of structurally normal MUC genes may be an important step in the neoplastic molecular pathway of a subset of CRCs and that mutations involving VNTR repetitive sequences may exist in MSI tumors as a direct and/or indirect consequence of an inefficient MMR system.
\end{abstract}

Keywords: Colon cancer, MSI, mucin, VNTR, mismatch repair

\section{Introduction}

Several studies have been carried out to elucidate the molecular pathways involved in the multistep process of the colorectal carcinogenesis and, at present, the pathogenesis of colon cancer (CRC) is one of the best known. In particular, several efforts have been made to understand the molecular bases of microsatellite instability (MSI) and to identify the genes, which are target for mutations in the presence of a defective mismatch repair (MMR) apparatus, and their con-

*Corresponding author: Alessandra Viel, PhD, Department of Preclinical Research and Epidemiology, Centro Riferimento Oncologico, IRCCS, Aviano (PN), Italy. Tel.: +39 0434 659671; Fax: +390434 659659; E-mail: aviel@cro.it. tribution to tumor progression. It is widely accepted that the entire carcinogenesis process of MMR deficient intestinal cells is sustained by the mutator phenotype. Although there are probably additional mechanisms through which deficient DNA MMR may lead to tumor formation, colon carcinogenesis appears to be driven mainly by loss of postreplicative mismatch correction, with the accumulation of somatic point mutations (expecially small insertions or deletions) in multiple growth regulatory target genes, such as TGF $\beta R$-II, E2F4 and $B A X[2,14]$.

CRCs developing in Hereditary Non Polyposis Colorectal Cancer (HNPCC) patients with constitutional mutations in $M S H 2$ or $M L H 1$ genes always display the MSI phenotype. However, MSI, the hallmark of MMR deficiency, may also be due to transcriptional silencing 
of the $M L H 1$ gene and this phenomenon concerns the majority of the MSI sporadic cases [13,14].

Peculiar histologic features are significantly associated with the MSI colon tumors, both sporadic and hereditary. In particular, CRCs with MSI are more often mucin-producing than tumors with microsatellite stability (MSS) and, conversely, mucinous CRCs display MSI more often than non-mucinous tumors $[3,11$, $15,16,18]$. In line with the strong association between HNPCC and MSI, it is not surprising that the mucinous histology, having a high incidence of MSI, has often been reported in HNPCC-related tumors [11].

Mucinous CRCs are characterized by mucin(s) overexpression, but it is not completely clear whether this property may be ascribable to variations in transcription/translation and/or glycosylation of apomucins. Moreover, information on possible gene abnormalities is lacking [1,22]. MUC genes are a family of genes containing long stretches of tandem repeats encoding Thr/Ser/Pro-rich domains. Each of these units has a specific length and sequence, and in several $M U C$ genes their repetitions vary individually according to a genetic polymorphism $[9,20]$. These Variable Number Tandem Repetition (VNTR) regions codify for the major portion of the peptide cores that are heavily glycosylated and display antigenic properties. The importance of these molecules to the course of tumor disease is related to their role in cell adhesion and metastasis, their diagnostic and prognostic relevance and their immunotherapeutic potential utility $[1,22]$.

By considering the observed association between MSI and mucinous CRCs, a molecular link between MSI and mucin overproduction may be suspected, but at present, it is not clear which molecular mechanisms are responsible for this phenomenon. Aim of this study was verifying whether mucin-producing CRCs with MSI could develop MUC gene alterations.

\section{Materials and methods}

\subsection{Patients and tissues}

Fourty-nine CRCs localized in the proximal colon were studied. This series comprises 27 sporadic patients and 22 patients with ascertained or suspected genetic predisposition (clinical diagnosis of HNPCC and/or positive CRC family history and/or early onset and/or multiple HNPCC-related tumors). Fifteen cases of the latter group had been previously screened for $M M R$ gene mutations, leading to the identification of 8 mutated tumors ( $6 M S H 2$ and $2 M L H 1,7$ constitutional and 1 somatic). Data on mucin production were collected by consultation of the pathologic reports, and tumors were classified as $++(10$ cases reported as mucinous histology or with prevalent mucinous components or $\geqslant 50 \%$ mucus $),+(28$ cases with partial/focal mucinous components or $<50 \%$ mucus $)$ and - (11 cases without mucus).

\subsection{Molecular analyses}

Genomic DNA was extracted from frozen tumors by the DNAeasy tissue kit (Qiagen GmbH, Hilden, Germany) following manufacturer's instructions. Corresponding blood or normal tissues were also used for DNA extraction and analysis.

MSI was evaluated using the standard NCI panel [4] by fluorescent-PCR analyses on an ABI 310 automatic sequencer (Applera, Foster City, CA, USA).

The VNTR regions of the MUC1, MUC2, MUC4, and $M U C 5 A C$ genes, characterized by repetitions of 24-69 bp highly polymorphic in length, were studied by Southern blotting. For VNTR sizing, normal and tumor DNAs were digested using either HinfI or PvuII restriction enzymes, electrophoresed through $0.8-1 \%$ agarose gels, blotted and hybridized to ${ }^{32} \mathrm{P}$-labelled probes by standard methods. TaqI digestion was also used on a limited number of cases. The $M U C$ probes were obtained by PCR and plasmid cloning (PGEMT vector Systems, Promega, Madison, WI, USA) and contained a minimum of 3 gene-specific Tandem Repeat units (details will be given on request).

\section{Results}

\subsection{MSI}

Twenty-two tumors (44.9\%) had high-level MSI (MSI-H), 5 (10.2\%) had low-level MSI (MSI-L), and the remaining $22(44.9 \%)$ were microsatellite stable (MSS). The high prevalence of MSI (55.1\%) was clearly ascribable to the peculiarity of the series analyzed, which was a collection of 49 CRCs comprising exclusively proximal tumors, about three fourths mucin producing, and nearly one half from ascertained or presumed hereditary cases.

Twenty-three out of the 27 MSI-H/MSI-L CRCs had variable amount of mucus $(++$ or +$)$. Conversely, among the 38 mucin producing CRCs, there was a slight excess of MSI (23 MSI-H/MSI-L, 60.5\%) in compari- 


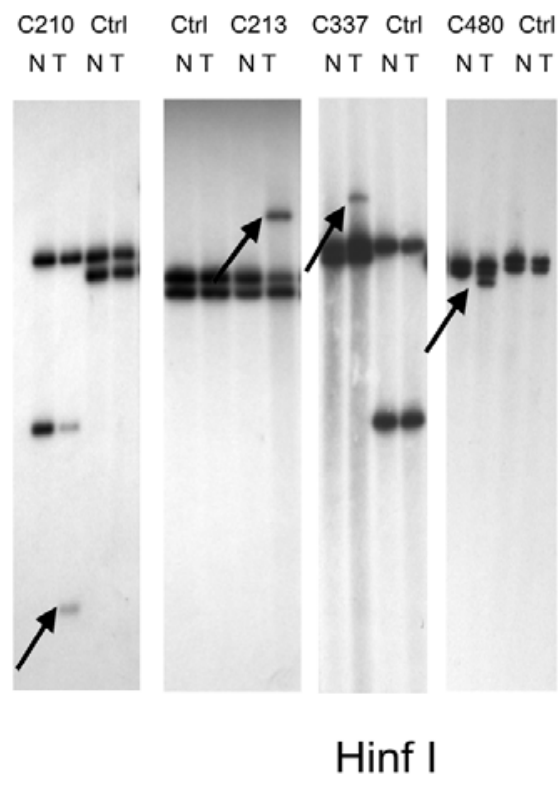

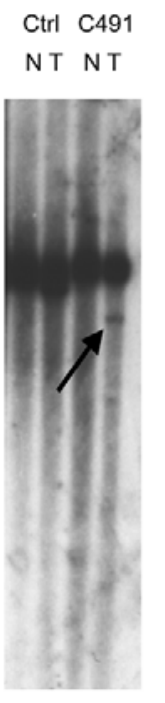

Hinf I

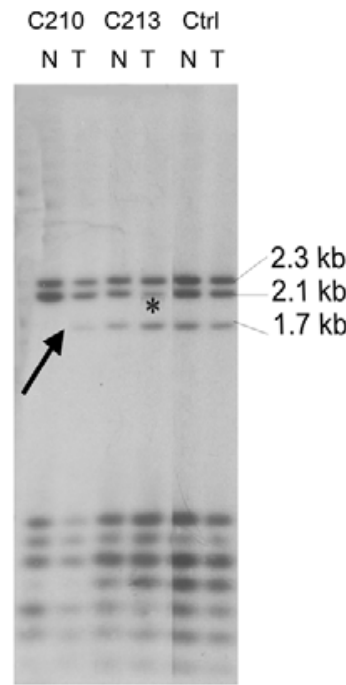

Taq I

Fig. 1. Southern blot analysis of the MUC2 VNTR. DNA was digested by HinfI (5 panels on the left) or TaqI (right panel). Ctrl, cases not displaying abnormalities; N, normal DNA; T, tumor DNA. Abnormal fragments in tumor DNAs are indicated by arrows and partial loss of heterozygosity is indicated by an asterisk. In the TaqI panel, the $2.3 \mathrm{~kb}$ band represents a constant fragment, whereas the alternative 2.1 and $1.7 \mathrm{~kb}$ bands derive from a sequence RFLP within the VNTR region.

son with the $11 \mathrm{CRCs}$ without mucus (4 MSI-H/MSI-L, $36.4 \%$ ). Fourteen of the patients with MSI tumors had an HNPCC-related personal and/or family history, and 7 of them had a constitutional $M S H 2$ or $M L H 1$ gene mutation. With the exception of a somatic $\mathrm{MSH} 2 \mathrm{mu}-$ tation in a (supposedly) hereditary tumor, $M L H 1$ promoter hypermetylation was probably the major contributor to the instability of the remaining 6 hereditary and 13 sporadic MSI cases.

\subsection{MUC genes}

Southern blot analyses were carried out to study the VNTR region of the $M U C 1, M U C 2, M U C 4$ and MUC5AC genes. HinfI digestion could be applied to all 49 cases for the analysis of $M U C 1, M U C 2$ and $M U C 5 A C$ genes, whereas $P v u I I$ restriction was limited to the study of MUC4 and MUC5AC genes in the 40 tumors for which sufficient amount of DNA was available. Moreover, TaqI was used to integrate the MUC2 analysis of 4 tumors.

Extra bands were evident at the DNA tumor level in MUC2 (5 cases) and MUC5AC (2 cases) (Figs 1, 2 and Table 1), but not MUC1 and MUC4 genes. All these tumors had a mucinous component $(3++$ and $4+)$. Interestingly, 6 out of the 7 somatic $M U C$ gene mutations were detected in MSI-H tumors and only one

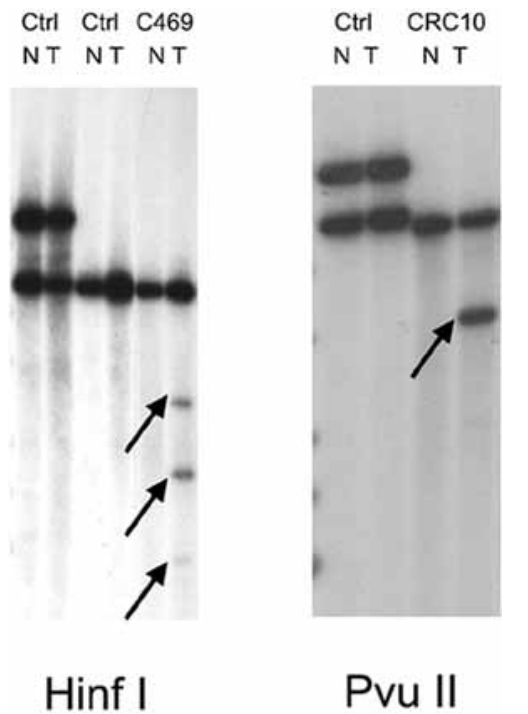

Fig. 2. Southern blot analysis of the MUC5AC VNTR. DNA was digested by HinfI (left panel) or PvuII (right panel). Ctrl, cases not displaying abnormalities; N, normal DNA; T, tumor DNA. Abnormal fragments in tumor DNAs are indicated by arrows.

was displayed by a MSI-L tumor (Table 1). Therefore, abnormalities of the VNTR sequences of MUC2 and MUC5AC genes, consisting of both increased and decreased allele sizes, seem to be peculiar of the CRCs with mucin and MSI (7/27 MSI-H/MSI-L and 0/22 
Table 1

$M U C$-genes abnormalities and tumor characteristics

\begin{tabular}{|c|c|c|c|c|c|c|c|c|}
\hline CRC ID & $\begin{array}{l}\text { HNPCC } \\
\text { history }^{a}\end{array}$ & Mucin $^{b}$ & MSI & $\mathrm{MMR}^{\mathrm{c}}$ & $\begin{array}{l}M U C 2 \mathrm{~kb} \\
(\operatorname{Hinf} \mathrm{I})^{\mathrm{d}}\end{array}$ & $\begin{array}{l}M U C 2 \mathrm{~kb} \\
(\operatorname{Taq~I})^{\mathrm{d}, \mathrm{e}}\end{array}$ & $\begin{array}{l}M U C 5 A C \mathrm{~kb} \\
(\operatorname{Hinf} \mathrm{I})^{\mathrm{d}}\end{array}$ & $\begin{array}{l}M U C 5 A C \mathrm{~kb} \\
(\mathrm{Pvu} \mathrm{II})^{\mathrm{d}}\end{array}$ \\
\hline $\mathrm{C} 210 \mathrm{~T}$ & - & ++ & MSI-L & NT & $7.8-4.2-(2.5)$ & $2.1-(1.7)$ & 6.6 & $6.8-6.6$ \\
\hline $\mathrm{C} 213 \mathrm{~T}$ & + & + & MSI-H & NT & (10.5) -7.8-7.0 & $2.1-1.7^{f}$ & 6.6 & 6.6 \\
\hline $\mathrm{C} 337 \mathrm{~T}$ & + & + & MSI-H & MLH1 & (10.0)-7.8-7.5 & $2.1-1.7$ & 6.6 & $6.8-6.6$ \\
\hline $\mathrm{C} 469 \mathrm{~T}$ & + & ++ & MSI-H & WT & $7.8-7.5$ & NT & $6.6-(4.4-3.6-2.0)$ & 6.6 \\
\hline C480T & + & + & MSI-H & NT & $7.8-7.0-(6.5)$ & $2.1-1.7$ & 6.6 & $6.8-6.6$ \\
\hline C491T & + & ++ & MSI-H & WT & $7.8-7.3-(5.8)$ & NT & 6.6 & 6.6 \\
\hline CRC10T & + & + & MSI-H & MSH2 & $7.8-7.5$ & NT & 6.6 & $6.6-(5.0)$ \\
\hline
\end{tabular}

$\mathrm{a}_{+}$, personal and/or family history positive for HNPCC tumors; - , personal and family history negative for HNPCC tumors.

$\mathrm{b}_{+}+$, mucinous histology or with prevalent mucinous components or $\geqslant 50 \%$ mucus; + , partial/focal mucinous components or $<50 \%$ mucus. ${ }^{\mathrm{c}} \mathrm{NT}$, Not tested for MMR gene mutations; WT, wild type; $M L H 1$ and $M S H 2$, mutated genes. ${ }^{\mathrm{d}}$ VNTR restriction fragments. Abnormal new bands in tumor DNA are reported in parentheses. ${ }^{\mathrm{e}}$ TaqI digestion also produced a $2.3 \mathrm{~kb}$ constant band and $6-7$ additional small $(\leqslant 0.5 \mathrm{~kb})$ fragments. ${ }^{\mathrm{f}}$ Partial loss of heterozygosity.

MSS; $p=0.0123$, Fisher exact test). Since only 2 cases were from patients with an MMR constitutional defect (Table 1), the MUC mutations appear independent on the mechanism leading to $M M R$ inactivation.

\section{Conclusion}

In this study, the $M U C$ analysis was restricted to 4 genes coding mucins that are variably produced in gastrointestinal normal epithelia and whose expression appears deregulated in colon tumors [1,3,22]. We chose $M U C 2$ and $M U C 5 A C$ as a model for the "secretory mucins", which are normally produced and secreted by goblet cells and, together with other gel-forming mucins, are the major constituents of mucus. We also chose MUC1 and MUC4 as models for the "membranebound mucins", which are transmembrane glycoproteins with anti-adhesive properties, exerting a role in tumor progression and metastasis.

Under our experimental conditions, 25.9\% of MSIH/MSI-L CRCs displayed DNA anomalies restricted to the genes coding for the secretory gel forming mucins. It is noteworthy that a major involvement of the secretory mucins in the pathogenesis of the unstable tumors has also been suggested by Biemer-Hüttmann et al. [3], who reported selective increased expression of the MUC2 and MUC5AC mucins, but not MUC1 and $M U C 4$, in sporadic CRCs with MSI-H. This immunohistochemical study was realized by means of monoclonal antibodies directed toward the VNTR region (MUC2) or the $\mathrm{COOH}$-terminus (MUC5AC) of the corresponding apomucins. However, it is not clear if this high immunoreactivity derives from an increased mRNA/protein synthesis or an increased exposure of the core protein epitopes due to changes in glycosylation or structural modifications of the apomucin.
In at least 4 of our $M U C$-mutated tumors (C210T, C213T, C480T and CRC10T) the relative amount of the anomalous fragments was considerable, suggesting that one of the two MUC alleles can be abnormal in at least $50 \%$ of tumor cells (100\% in CRC10T). This observation opens the question on the possible existence of a positive selective pressure in favor of the unstable tumor cells with a $M U C$-gene anomaly. Notably, nullizygous mice with targeted inactivation of the $M U C 2$ gene displayed aberrant intestinal crypt morphology, altered cell maturation and migration and increased tumor formation with spontaneous progression to invasive cancer [24]. Thus, normal MUC2 gene could really be involved in the suppression of colon carcinogenesis.

The exact nature of the VNTR abnormal fragments is presently unknown, but their discovery restricted to MSI tumors implies that the effect of MMR gene inactivation in some CRCs may go beyond the classical mutator phenotype, characterized by alteration in the size of microsatellite DNA sequences. In some cases, they could simply derive from point mutations generating new RFLPs. This could be the case of MUC5AC gene, which displayed abnormalities with only one or the other of the two enzymes used in the analysis (HinfI or $P v u I I)$, cutting inside a complex sequence with tandem repeats alternating to Cys-rich domains. Alternatively, the aberrant fragments could be due to a real change of the VNTR size and this could have occurred for some MUC2 mutations. The MUC2 gene exhibits a VNTR size polymorphism that is easily detectable by the enzyme HinfI, whereas changes of the VNTR length are expected to affect the TaqI digestion-pattern mainly at the level of the smaller fragments $(\leqslant 0.5 \mathrm{~kb})$ containing multiples of the tandem repeat units [23]. Unfortunately, qualitative and/or quantitative variations of this pattern were hardly appreciable on our experimental conditions, and this did not allow us to definitely con- 
firm the VNTR size changes with two different digestion approaches. However, TaqI enzyme also revealed a sequence RFLP located within the $3^{\prime}$ portion of VNTR region [23] and the novel $1.7 \mathrm{~kb}$ TaqI-fragment in tumor $\mathrm{C} 210 \mathrm{~T}$ and the apparent loss of heterozygosity in tumor C213T (Fig. 1) could also be related to the $M U C 2$ VNTR mutations/rearrangements detected by HinfI.

Defective processes of homologous recombination might explain our findings in some MSI tumors. In fact, apart from postreplicative mismatch correction, MMR proteins coordinate a complex network of physical and functional interactions that can be relevant to carcinogenesis [2], including post-replicative DNA-damage signaling and apoptosis [12,26], base excision repair [5] and prevention of recombination between nonidentical sequences (homeologous recombination) [21]. In agreement with these theories, in yeast MMR machinery imposes a barrier to recombination between sequences of low divergence [6]. Accordingly, loss of MMR in mammals results in an increased frequency of recombination between diverged sequences and in longer gene conversion tracts [7,8]. Homologous recombination is an important DNA-repair pathway leading to correction of double-strand-breaks (DSBs) produced by exogenous damaging agents and by replication errors, and it has been recently suggested that deletion or insertion mutations associated with DSBs represent a novel mechanism by which $\mathrm{MSH} 2$-deficiency could promote cancer-associated mutations [25]. Thus, our findings might be consistent with a direct role of the MMR system in the control of reparative recombination involving VNTR sequences.

Alternatively, MMR deficiency itself could not be directly responsible for the observed effect, but loss of correct homologous recombination or other DSB repair processes could be the result of events downstream the loss of MMR, such as mutations of RAD50, BLM, $M R E 11$ and XRCC2 target genes [10,17,19]. According to this hypothesis, $5 M U C$-mutated tumors had also $R A D 50$ ( 2 cases) and/or MRE11 (4 cases) somatic mutations [10].

In conclusion, this study indicates a possible link between MSI and $M U C$ gene abnormalities and suggests that alteration and/or loss of structurally normal $M U C$ genes may be an important step in the neoplastic molecular pathway of a subset of colon tumors. Although frameshift mutations in several growth regulatory target genes represent the most significant consequence of the mutator phenotype, mutations involving VNTR repetitive sequences may also exist in MSI tumors as a direct and/or indirect consequence of an inefficient MMR system.

\section{Acknowledgements}

This work was supported by the Italian Ministry of Health, RF FSN 2001-ICS117 (to A.V.)

\section{References}

[1] S.E. Baldus and F.G. Hanisch, Biochemistry and pathological importance of mucin-associated antigens in gastrointestinal neoplasia, Adv Cancer Res 79 (2000), 201-248.

[2] A. Bellacosa, Functional interactions and signaling properties of mammalian DNA mismatch repair proteins, Cell Death Differ 8 (2001), 1076-1092.

[3] A.E. Biemer-Hüttmann, M.D. Walsh, M.A. McGuckin, L.A. Simms, J. Young, B.A. Leggett and J.R. Jass, Mucin core protein expression in colorectal cancers with high levels of microsatellite instability indicates a novel pathway of morphogenesis, Clin Cancer Res 6 (2000), 1909-1916.

[4] R.C. Boland, S.N. Thibodeau, S.R. Hamilton, D. Sidransky, J.R. Eshleman, R.W. Burt, S.J. Meltzer, M.A. RodriguezBigas, R. Fodde, G.N. Ranzani and S. Srivastava, A National Cancer Institute workshop on microsatellite instability for cancer detection and familial predisposition: development of international criteria for the determination of microsatellite instability in colorectal cancer, Cancer Res 58 (1998), 52485257.

[5] S. Cortellino, D. Turner, V. Masciullo, F. Schepis, D. Albino, R. Daniel, A.M. Skalka, N.J. Meropol, C. Alberti, L. Larue and A. Bellacosa, The base excision repair enzyme MED1 mediates DNA damage response to antitumor drugs and is associated with mismatch repair system integrity, Proc Natl Acad Sci USA 25 (2003), 15071-15076.

[6] A. Datta, M. Hendrix, M. Lipsitch and S. Jinks-Robertson, Dual roles for DNA sequence identity and the mismatch repair system in the regulation of mitotic crossing-over in yeast, Proc Natl Acad Sci USA 94 (1997), 9757-9762.

[7] N. de Wind, M. Dekker, A. Berns, M. Radman and H. te Riele, Inactivation of the mouse $\mathrm{MSH} 2$ gene results in mismatch repair deficiency, methylation tolerance, hyperrecombination, and predisposition to cancer, Cell 82 (1995), 321-330.

[8] B. Elliott and M. Jasin, Repair of double-strand breaks by homologous recombination in mismatch repair-defective mammalian cells, Mol Cell Biol 21 (2001), 2671-2682.

[9] J. Fowler, L. Vinall and D. Swallow, Polymorphism of the human MUC genes, Front Biosci 6 (2001), d1207-d1215.

[10] G. Giannini, C. Rinaldi, E. Ristori, M.I. Ambrosini, F. Cerignoli, A. Viel, E. Bidoli, S. Berni, G. D’Amati, G. Scambia, L. Frati, I. Screpanti and A. Gulino, Mutations of an intronic repeat induce impaired MRE11 expression in primary human cancer with microsatellite instability, Oncogene 23 (2004), 2640-2647.

[11] C. Hanski, Is mucinous carcinoma of the colorectum a distinct genetic entity? Br J Cancer 72 (1995), 1350-1356.

[12] M.T. Hawn, A. Umar, J.M. Carethers, G. Marra, T.A. Kunkel, C.R. Boland and M. Koi, Evidence for a connection between the mismatch repair system and the $\mathrm{G} 2$ cell cycle checkpoint, Cancer Res 17 (1995), 3721-3725.

[13] J.G. Herman, A. Umar, K. Polyak, J.R. Graff, N. Ahuja, J.-P.J. Issa, S. Markowitz, J.K.V. Willson, S.R. Hamilton, K.W. Kinzler, M.F. Kane, R.D. Kolodner, B. Vogelstein, T.A. Kunkel and S.B. Baylin, Incidence and functional consequences of 
hMLH1 promoter hypermethylation in colorectal carcinoma, Proc Natl Acad Sci USA 95 (1998), 6870-6875.

[14] J. Jiricny and G. Marra, DNA repair defects in colon cancer, Curr Opin Genet Dev 13 (2003), 61-69.

[15] S. Kakar, S. Aksoy, L.J. Burgart and T.C. Smyrk, Mucinous carcinoma of the colon: Correlation of loss of mismatch repair enzymes with clinicopathologic features and survival, Mod Pathol 17 (2004), 696-700.

[16] H. Kim, J. Jen, B. Vogelstein and S.R. Hamilton, Clinical and pathological characteristics of sporadic colorectal carcinomas with DNA replication errors in microsatellite sequences, $\mathrm{Am}$ J Pathol 145 (1994), 148-156.

[17] N.G. Kim, Y.R. Choi, M.J. Baek, Y.H. Kim, H. Kang, N.K. Kim, J.S. Min and H. Kim, Frameshift mutations at coding mononucleotide repeats of the hRAD50 gene in gastrointestinal carcinomas with microsatellite instability, Cancer Res $\mathbf{6 1}$ (2001), 36-38.

[18] L. Messerini, F. Vitelli, L.R. De Vitis, S. Mori, A. Calzolari, R. Palmirotta, A. Calabrò and L. Papi, Microsatellite instability in sporadic mucinous colorectal carcinomas: Relationship to clinico-pathological variables, J Pathol 182 (1997), 380-384.

[19] A. Mohindra, L.E. Hays, E.N. Phillips, B.D. Preston, T. Helleday and M. Meuth, Defects in homologous recombination repair in mismatch-repair-deficient tumour cell lines, Hum Mol Genet 11 (2002), 2189-2200.
[20] N. Moniaux, F. Escande, N. Porchet, J.P. Aubert and S.K. Batra, Structural organization and classification of the human mucin genes, Front Biosci 6 (2001), d1192-d1206.

[21] M. Radman, Mismatch repair and the fidelity of genetic recombination, Genome 1 (1989), 68-73.

[22] E. Seregni, C. Botti, S. Massaron, C. Lombardo, A. Capobianco, A. Bogni and E. Bombardieri, Structure, function and gene expression of epithelial mucins, Tumori 83 (1997), 625632.

[23] N.W. Toribara, J.R. Gum, P.J. Culhane, R.E. Lagace, J.W. Hicks, G.M. Petersen and Y.S. Kim, $M U C-2$ human small intestinal mucin gene structure, J Clin Invest 88 (1991), 10051013.

[24] A. Velcich, W.C. Yang, J. Heyer, A. Fragale, C. Nicholas, S. Viani, R. Kucherlapati, M. Lipkin, Y. Kan and L. Augenlicht, Colorectal cancer in mice genetically deficient in the mucin MUC2, Science 295 (2002), 1726-1729.

[25] J.F. Villemure, C. Abaji, I. Cousineau and A. Belmaaza, MSH2-deficient human cells exhibit a defect in the accurate termination of homology-directed repair of DNA doublestrand breaks, Cancer Res 63 (2003), 3334-3339.

[26] H. Zhang, B. Richards, T. Wilson, M. Lloyd, A. Cranston, A. Thorburn, R. Fishel and M. Meuth, Apoptosis induced by overexpression of hMSH2 or hMLH1, Cancer Res 13 (1999), 3021-3027. 


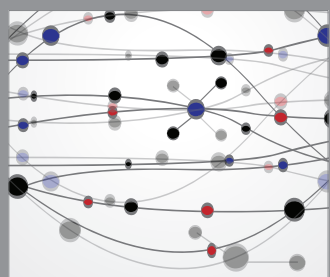

The Scientific World Journal
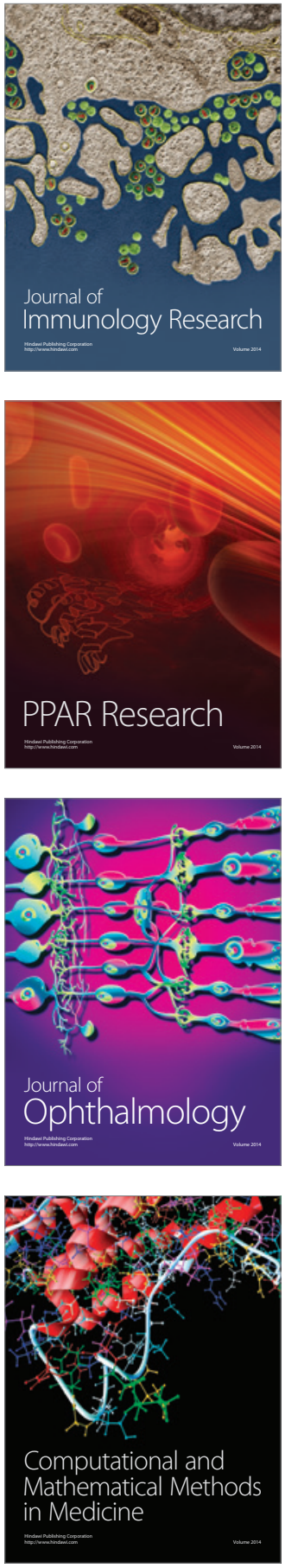

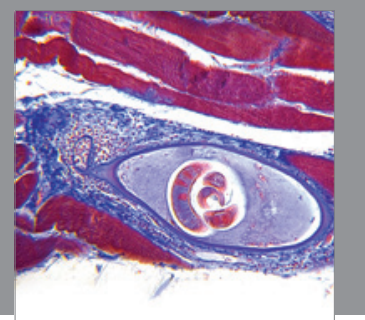

Gastroenterology

Research and Practice
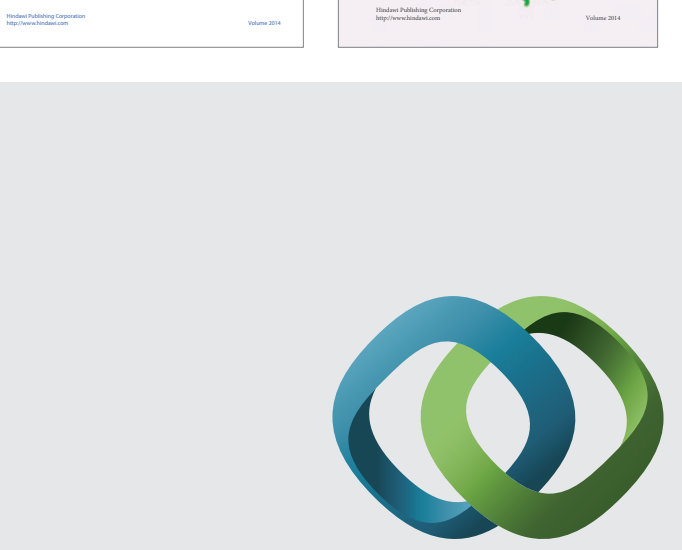

\section{Hindawi}

Submit your manuscripts at

http://www.hindawi.com
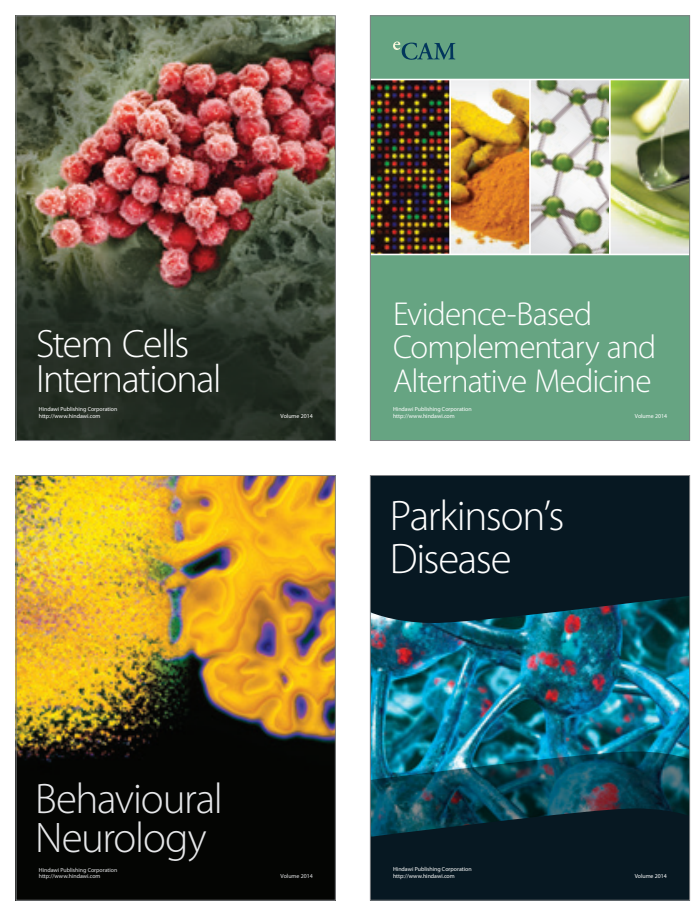

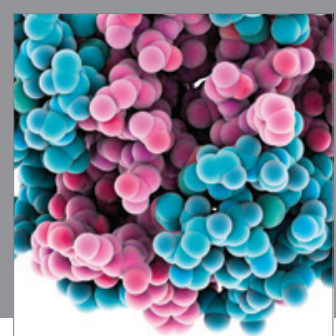

Journal of
Diabetes Research

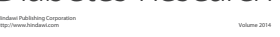

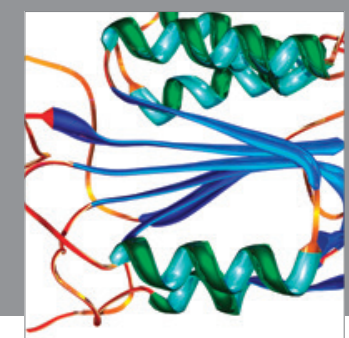

Disease Markers
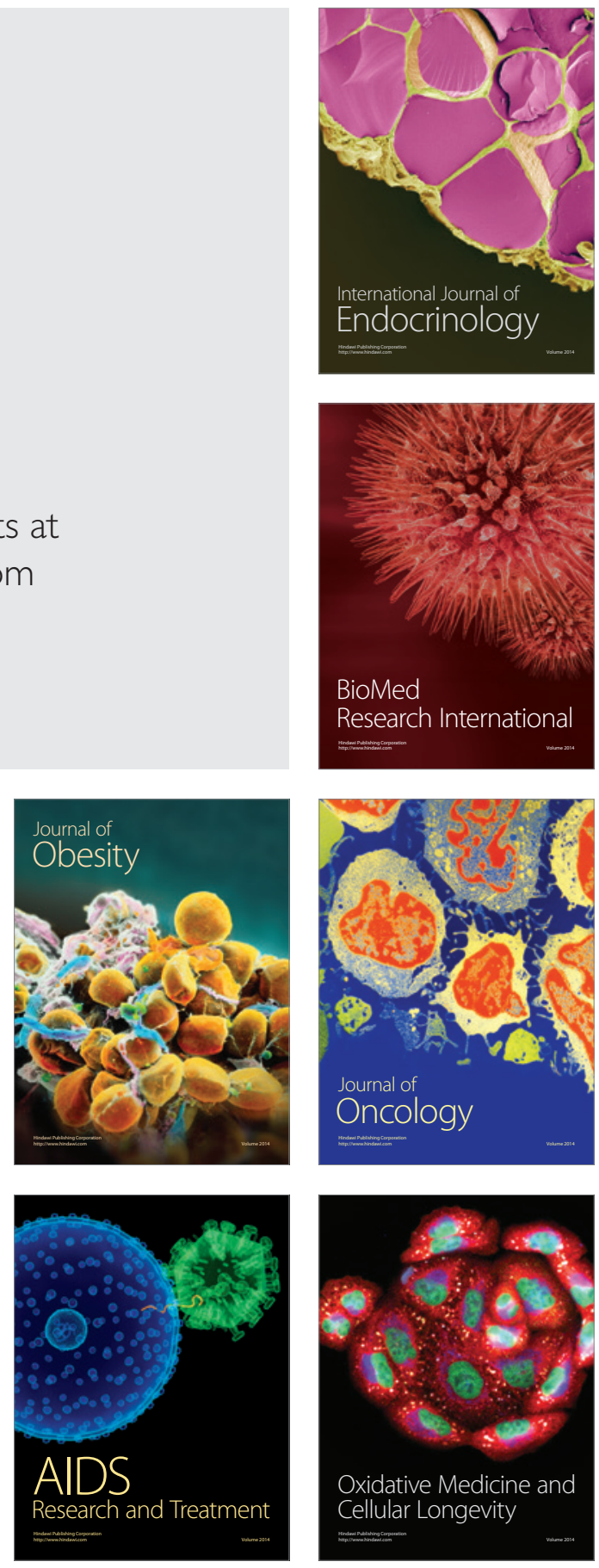